\title{
Prediction of Residual Life of Isolating Materials in the Process of Thermal Power Equipment Deterioration
}

\author{
Dubyago M.N. ${ }^{1, \text { a }}$ and Poluyanovich N.K., ${ }^{2, b}$ \\ ${ }^{1}$ Department of Electrical Sciences and Mechatronics, Southern Federal University, \\ Taganrog, Russian Federation \\ 2 Department of Electrical Sciences and Mechatronics, Southern Federal University, \\ Taganrog, Russian Federation \\ aw_m88@mail.ru, bnik1-58@mail.ru,
}

Keywords: Cable insulation, thermodynamic processes, partial discharges, destruction.

Abstract. Methods of calculation of thermal processes of the isolating materials are considered, in problems of nondestructive diagnostics of the main and distributive power stations. Theoretical justification of calculation of thermal processes of the multilayered isolating structure was given. On the basis of the analysis of results of operation, service life, physical processes of "ageing" and use of diagnostic parameters of the isolating structure characteristics of resistance of the equipment to refusal are offered. Time of refusal and a residual service life allow to predict using of dependences of refusal resistance.

\section{Introduction}

Temperature is one of the major factors defining wear and destruction of the isolating materials, power stations. If temperature becomes nearer to the most admissible, begins process of intensive thermal wear of the isolating material, its thermal aging. As a result can occur thermal breakdown of the isolating material. Factors of environment and electromagnetic processes complicate a task of the analysis of the thermal modes, from the point of view of heating engineers, on some orders.

\section{Model of thermal processes}

The mathematical model of thermal processes of the isolating material [1], doesn't consider a number of factors of the isolating materials influencing heating - dielectric losses, superficial effect in veins, losses in the screen, a way of screen grounding. In the work is considered the mathematical model of thermal processes of the power cable line (PCL) which isn't using empirical coefficients and dependences, but allowing a message calculation of temperature of the most heated point of isolation of a cable with a sufficient accuracy. Write down the system of the differential equations for thermal processes of single-core PCL considering specific factors where: $\theta_{1}-\theta_{5}$ - temperatures of uniform bodies (Fig.2; $\mathrm{C}_{1}-\mathrm{C}_{4}-$ thermal resistance of the corresponding uniform bodies; $\mathrm{P}_{1}-\mathrm{P}_{4}-$ losses of active power, respectively, in a current carrying vein, isolation of a vein, the screen and a protective cover.

$$
\left\{\begin{array}{c}
\mathrm{C}_{1} \cdot \mathrm{d} \theta_{1} / \mathrm{dt}+\left(\theta_{1}-\theta_{2}\right) / \mathrm{R}_{1}=\mathrm{P}_{1} \\
\mathrm{C}_{2} \cdot \mathrm{d} \theta_{2} / \mathrm{dt}+\left(\theta_{2}-\theta_{1}\right) / \mathrm{R}_{1}+\left(\theta_{2}-\theta_{3}\right) / \mathrm{R}_{2}=\mathrm{P}_{2} \\
\mathrm{C}_{3} \cdot \mathrm{d} \theta_{3} / \mathrm{dt}+\left(\theta_{3}-\theta_{2}\right) / \mathrm{R}_{2}+\left(\theta_{3}-\theta_{4}\right) / \mathrm{R}_{2}=\mathrm{P}_{3} \\
\mathrm{C}_{4} \cdot \mathrm{d} \theta_{4} / \mathrm{dt}+\left(\theta_{2}-\theta_{1}\right) / \mathrm{R}_{3}+\left(\theta_{4}-\theta_{5}\right) / \mathrm{R}_{4}=\mathrm{P}_{4}
\end{array}\right.
$$

On the basis of system (1) is synthesized the thermal equivalent circuit of the isolating material, Fig. 1.

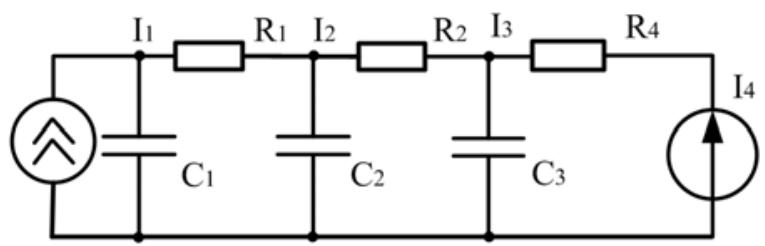

Figure 1 - Thermal equivalent circuit 
We can note that $\theta_{2}$ temperature of the most heated point of isolation of a cable (Fig. 2). Thermal capacities of uniform bodies, the APV power cable of PU-1x30/25-10 $\mathrm{C}_{1}-\mathrm{C}_{3}$ can be found on formulas:

$$
\left\{\begin{array}{c}
\mathrm{C}_{1}=\mathrm{c}_{1} \cdot \beta_{1} \cdot\left(\pi \cdot \mathrm{d}_{1}{ }^{2} / 4\right) \cdot \mathrm{l} \\
\mathrm{C}_{2}=\mathrm{c}_{2} \cdot \beta_{2} \cdot(\pi / 4) \cdot\left(\mathrm{d}_{2}^{2}-\mathrm{d}_{1}^{2}\right) \cdot \mathrm{l} \\
\mathrm{C}_{3}=\mathrm{c}_{3} \cdot \beta_{3} \cdot(\pi / 4) \cdot\left(\mathrm{d}_{3}^{2}-\mathrm{d}_{2}^{2}\right) \cdot \mathrm{l} \\
\mathrm{C}_{4}=\mathrm{c}_{4} \cdot \beta_{4} \cdot(\pi / 4) \cdot\left(\mathrm{d}_{5}^{2}-\mathrm{d}_{4}^{2}\right) \cdot 1
\end{array}\right.
$$

Thermal resistance of uniform bodies of PCL $\mathrm{R}_{1}-\mathrm{R}_{3}$ pay off on formulas:

$$
\begin{aligned}
& \mathrm{R}_{1}=1 /\left(2 \cdot \gamma_{1} \cdot \pi \cdot \mathrm{l}\right) \\
& \mathrm{R}_{2}=\left(\ln \left(\mathrm{d}_{2} / \mathrm{d}_{1}\right)\right) /\left(2 \cdot \gamma_{2} \cdot \pi \cdot \mathrm{l}\right) \\
& \mathrm{R}_{3}=\left(\ln \left(\mathrm{d}_{3} / \mathrm{d}_{2}\right)\right) /\left(2 \cdot \gamma_{3} \cdot \pi \cdot \mathrm{l}\right) \\
& \mathrm{R}_{4}=\left(\ln \left(\mathrm{d}_{5} / \mathrm{d}_{4}\right)\right) /\left(2 \cdot \gamma_{4} \cdot \pi \cdot \mathrm{l}\right)
\end{aligned}
$$

Heat conductivity of metals considerably exceeds heat conductivity of dielectrics therefore the ratio is fair: $R_{1} \ll R_{2} ; R_{1} \ll R_{3}$. Losses of power, taking into account dependence of resistance of a vein of a cable on temperature, are equal

$$
\mathrm{P}=\mathrm{I}^{2} \cdot \mathrm{R}_{\omega \mathrm{l}}=\mathrm{I}^{2} \cdot \rho 20 \cdot\left(1+\alpha \cdot\left(\theta_{1}-20\right)\right) \cdot\left((4 \cdot \mathrm{l}) /\left(\pi \cdot \mathrm{d}_{1}^{2}\right)\right)
$$

where I - the current proceeding on a vein of a cable $(\mathrm{A}) ; \mathrm{R}_{\mathrm{el}}$ - cable vein resistance length of 1 $(\mathrm{Ohm}) ; \rho 20-$ the specific resistance of material at a temperature $\theta_{1}=20^{\circ} \mathrm{C}(\mathrm{Om} . \mathrm{m}) ; \alpha-$ the temperature coefficient of resistance $(\mathrm{TCR})$ of material $\left(1 /{ }^{\circ} \mathrm{C}\right)$. Losses in a cable vein taking into account the phenomenon of superficial effect which is shown in increase in resistance of the conductor on alternating current of $\mathrm{R}_{\omega}$ in comparison with resistance on a direct current of $\mathrm{R}_{0}$, are equal:

$P_{1}=I_{1}^{2}\left(R_{\omega} / R_{0}\right) \rho 20\left(1+\alpha_{1}\left(\theta_{1}-20\right)\right)\left(l / \pi \cdot r_{1}^{2}\right)$,

where I1 - the current proceeding on a cable vein. The superficial effect in uniform cylindrical conductors is described as:

$$
\left\{\begin{array}{c}
\left(\mathrm{R}_{\omega} / \mathrm{R}_{0}\right)=1+\left(\mathrm{k}^{4} / 3\right) \quad \text { if } \mathrm{k}<1 \\
\left(\mathrm{R}_{\omega} / \mathrm{R}_{0}\right)=0,997 \cdot \mathrm{k}+0,277 \quad \text { if } 1<k<10 \\
\left(\mathrm{R}_{\omega} / \mathrm{R}_{0}\right)=\mathrm{k}+1 / 4+(3 / 64 \cdot \mathrm{k}) \text { if } \mathrm{k}>10 \\
\mathrm{k}=\left(\mathrm{r}_{1} \cdot \sqrt{2 \cdot \mu \cdot \mu_{0} \cdot \gamma \cdot \omega}\right) / 4
\end{array}\right.
$$

where $r_{1}$ - the radius of the conductor, especially cable vein radius; $\mu$ - relative magnetic permeability of material of a vein; $\gamma$ - specific conductivity of material of a vein.

Dielectric losses of $\mathrm{P}_{2}$ and $\mathrm{P}_{4}$ pay off on a formula $\mathrm{P}_{\mathrm{i}}=2 \cdot \pi \cdot \mathrm{U}_{\mathrm{i}}^{2} \cdot \mathrm{f} \cdot \mathrm{C}_{\mathrm{i}} \cdot \operatorname{tg} \delta_{\mathrm{i}}$, where $\mathrm{i}=\{2 ; 4\} ; \mathrm{U}_{\mathrm{i}}$ - isolation tension; $f$ - working frequency; $C_{i}$ - isolation capacity; $\operatorname{tg} \delta_{i}-$ a tangent of angle of dielectric losses of isolation. Value of tension of $U_{i}$ depends on a way of grounding of the screen of a cable. Generally it is possible to write down $\dot{U}_{2}=\dot{U}_{\phi}-\dot{U}_{3} ; \dot{U}_{4}=\dot{U}_{3}$, where $\dot{U}_{3}-$ complex value of tension on the cable screen concerning the earth. Isolation capacity for cylindrical condensates $\mathrm{C}_{\mathrm{i}}=\left(\pi \cdot \varepsilon_{\mathrm{i}} \cdot \varepsilon_{0} \cdot \mathrm{l}\right) /\left(\ln \left(\mathrm{r}_{\text {ext.i }} / \mathrm{r}_{\text {int.i }}\right)\right.$, where $\mathrm{r}_{\text {ext.i }}, \mathrm{r}_{\mathrm{int.i}}-$ isolation radiuses; $\varepsilon_{\mathrm{i}}-$ relative dielectric permeability of material; 1 - cable length. Losses of power in the P3 screen depend on a way of grounding of the screen of a cable. If the screen is grounded on the one hand, current through it is approximately equal to zero. Losses of power in the screen pay off on the operating value of current in the screen $I_{3}, P_{3}=I_{3}^{2} \cdot \rho 20\left(1+\alpha_{3}\left(\theta_{3}-20\right)\right)\left(l /\left(\left(r_{\text {ext. } 3}\right)^{2}-\left(r_{\text {int. } 3}\right)^{2}\right)\right)$, where $\rho 20-$ the specific 
resistance of the screen at a temperature of $20^{\circ} \mathrm{C} ; \alpha_{3}-$ screen material $\mathrm{SM} ; \mathrm{r}_{\text {ext.3 }}, \mathrm{r}_{\text {int.3 }}-$ external and internal radiuses of the screen; 1 - cable length. Having considered a thermal equivalent circuit (Fig.1), we will receive expression for the established value of the temperature of cable veins:

$$
\theta_{2 . \text { est. }}=P \cdot\left(R_{2}+R_{3}\right)+\theta_{4} \text {. }
$$

From comparison of ratios (4), (5), (7) and (9) it is understand that values of length of 1 also don't influence calculations for the set thermal mode.

\section{Modeling of thermal processes}

Data on the geometrical sizes of elements of the AP PU of - 1x30/25-10 and their help data [2,3,5]. are reduced in the Table 1. Design of a single-conductor power cable as system of thermal uniform bodies, it is presented on the Fig. 2.

Table 1. Diameters of a power cable

\begin{tabular}{|l|c|c|c|c|}
\hline Materials & $\begin{array}{l}\text { Cop- } \\
\text { per }\end{array}$ & XLPE & Lead & Air \\
\hline $\begin{array}{l}\text { Thermal } \\
\text { conductivity } \\
(\mathrm{W} /(\mathrm{m} \cdot \mathrm{k}))\end{array}$ & 400 & 0.38 & 34 & 0.024 \\
\hline Density $\left(\mathrm{kg} / \mathrm{m}^{3}\right)$ & 8700 & 2200 & 11370 & 1.2 \\
\hline $\begin{array}{l}\text { Specific heat } \\
(\mathrm{J} /(\mathrm{kg} \cdot \mathrm{k}))\end{array}$ & 385 & 1900 & 3000 & 1005 \\
\hline
\end{tabular}

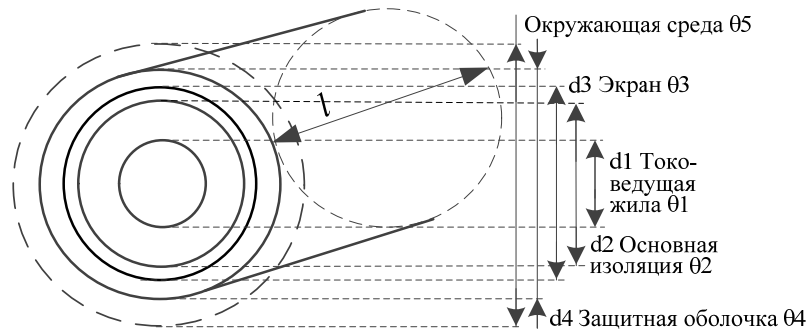

Figure 2 - System of uniform thermal bodies

Results of modeling. Modeling of non-stationary thermal processes in isolation of a power cable was carried out in the system of Mathcad. On the figure 3 is taken dependence of process of heating of a cable, on layers.

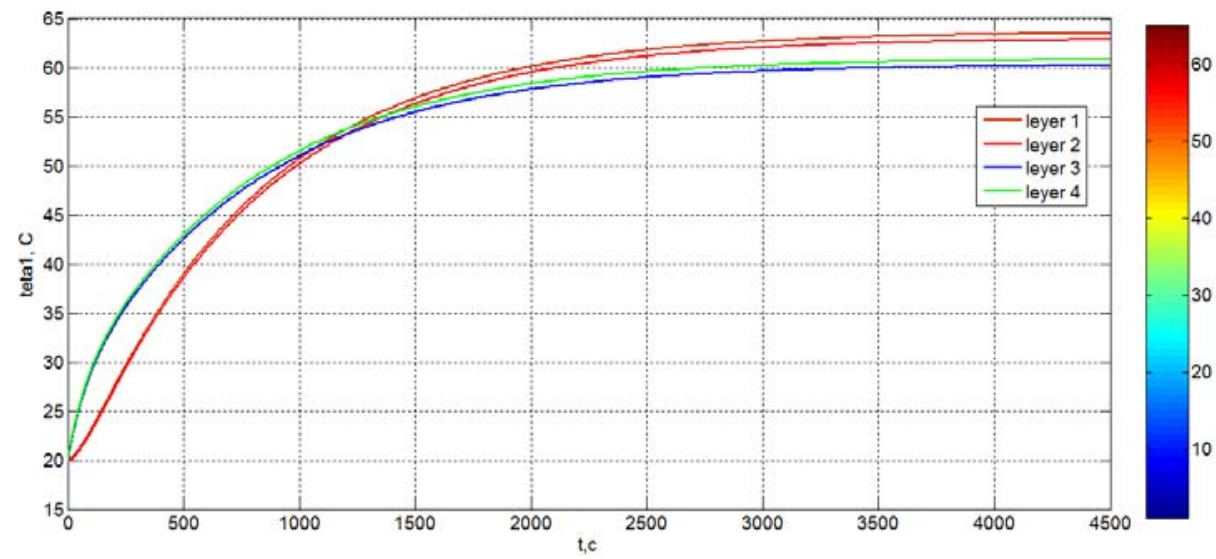

Figure 3 - Settlement chart of process of heating of the cable

The considered method of calculation of thermal processes can be applied to cables with any number of veins by increase in quantity of the equations in system (1).

Research of service life. Research of distribution of temperature and dynamics of its change it is executed in the program COMSOL MULTIPHYSYCS complex on the basis of a method of final elements. Basic data for calculation are the parameters specified in Tab. 1. We received the gradient of temperatures on the section of a cable, Fig. 4.a. Results of calculation of the set mode (Fig. 4.b) caused by the different current proceeding on a vein distinctly show weak, almost zero, dependence of distribution of temperature of high-heat-conducting elements - a vein and the screen of a cable (horizontal regiments on schedules). Thus in volume of isolation is observed the big gradient of 
temperatures that leads to an essential difference of temperatures of the screen of a cable where temperature sensors and the central vein are installed.

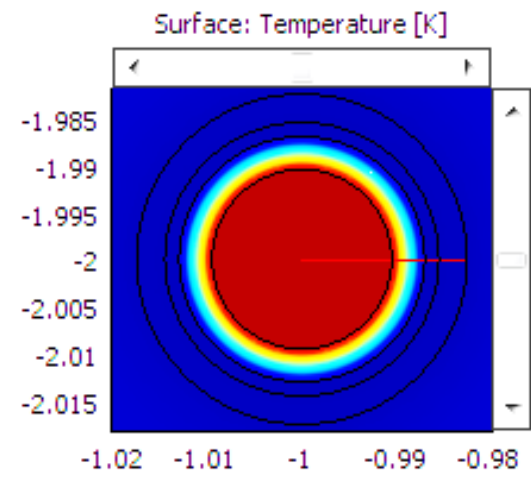

a)

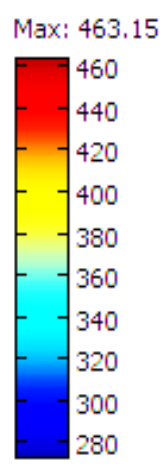

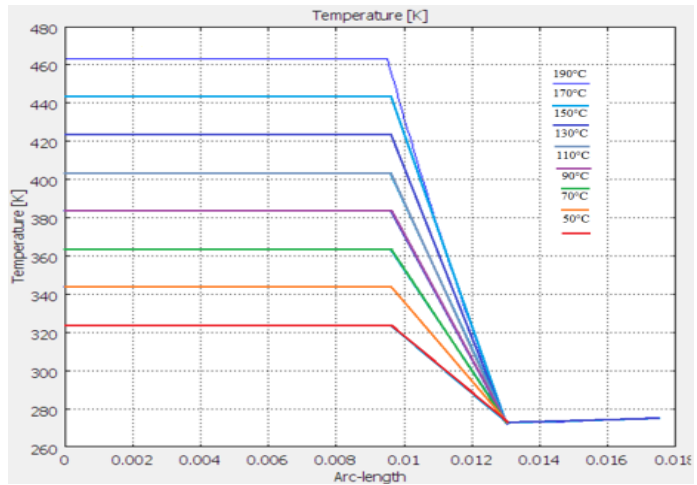

b)

Figure 4: $a$-Gradient of temperatures on the section; $b$ - Distribution of temperature in cable section at different temperatures on a vein

That is why, service life of the isolating materials of cables can be less than established $25-30$ years, as is confirmed in practice; the capacity calculated on design stages and actual can significantly differ[1].

\section{Resistance to equipment failure under operating conditions}

The operational resource time of life of $t$ of the main and distributive power stations feeling a complex of various influences is described by dependence [2].

$$
t=\Theta \cdot b^{a}
$$

where $\Theta$ the constant defining an initial condition of system, $b$ - the basis of an exponential function, a- describes changing character of function in time.

Service life of power stations it is described by dependence of a look

$$
t=\Theta \cdot\left[1-b^{a}\right]
$$

Nature of change of the function described by a formula (11) depends on value a.

If to accept the characteristic of resistance of object to refusal in the form of the $\Theta o t$ parameter, function (11) can be presented in the form

$$
\Theta(t)=\Theta o t\left[1-\left(t / t_{n}\right)^{a}\right]
$$

where $\Theta o t$ - resistance to refusal in an initial state, $\mathrm{t}$ - flowing time; $t_{n}$ - operating time to the full object; $t_{n}$ - statistical service life in the field of the maximum values:

-by commissioning object when $t=0$, value $\Theta o t$ is equal 1 ,

-by the ending of operation when $t=t_{n}$, Oot value is equal 0 .

That is why, $\Theta(t)$ is function of time of an operating time to the full and describes resistance of object to refusal, figure 6 , at various values of an indicator a.

Most closer exponential functions of a type oft $=A \cdot(1-b a)(1-b a)$ at a $=1,3-1,6$. Optimum value it is necessary to accept and $=1,5$. During the initial period of time of operation, fast wear of the equipment unlike the dependence having an indicator $a>1$ isn't observed. Materials which service life are described by the dependences having indicators $a>1 ; a<1$, can have finally the same time of a resource, $t_{\text {pec }}$ if there is no the accelerated aging at emergence of dangerous defects. If to consider the same object presented by dependences at $\mathrm{a}=1,5$ and $\mathrm{a}=0,5$ (Fig. 5), by the time formation of defect at the time of td which leads to identical deterioration of properties in the form of reduction of the $\Theta o t$ 
parameter by $\Delta \Theta o t$ and to various values of the predicted times of refusal of $t_{\mathrm{ot} 1}$ and $\mathrm{t}_{\mathrm{ot} 2}$. Thus it is assumed that after the moment of td regularities of aging remain. Function (12) after the moment of formation of defect can be presented in the form

$$
\Theta(t)=\Theta o t\left[1-\left(t / t_{n}\right)^{a}\right]-\Delta \Theta o t
$$

At $\Theta o t=0$ the current time will be refusal time $t=t_{\text {otk }}$, therefore,

$$
\Theta o t(t)=\Theta o t n\left[1-\left(t / t_{n}\right)^{a}\right]-\Delta \Theta o t=0
$$

Value $t_{\text {otk }}$ will be equal

$$
t_{o t k}=t_{n}\left[1-(1-\Delta \Theta o t)^{1 / a}\right]
$$

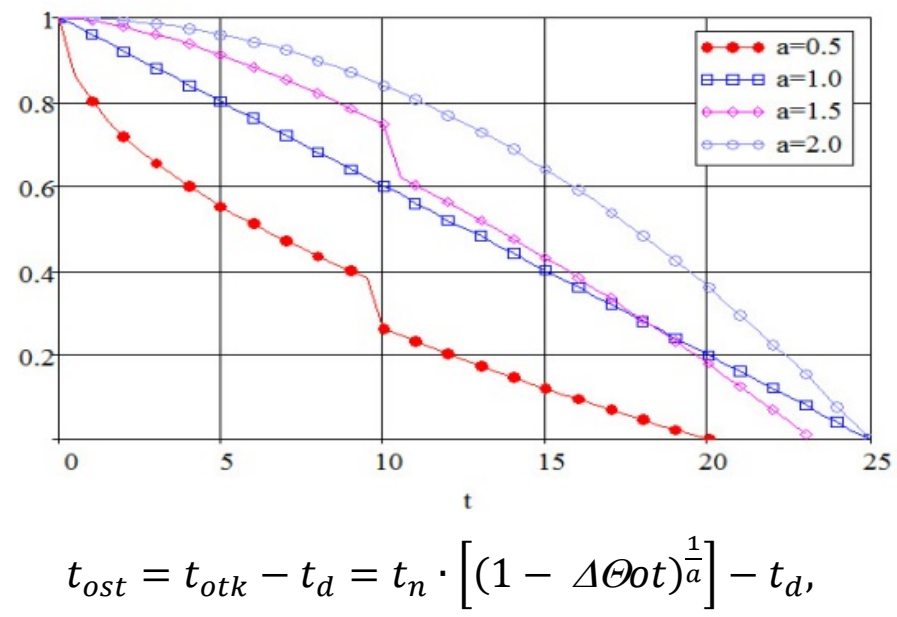

Figure 5 - Functions of resistance to refusal at formation of defect and a residual resource respectively

Formation of defect in a time point of $\mathrm{t}_{1}$ and $\mathrm{t}_{2}$ (Fig. 6) leads to reduction of resistance to refusal that will be expressed in decrease in $\Theta o t$ value on $\Delta \Theta o t$. Elimination of part of defects in the period of $t_{3}$ leads to increase in relative resistance to refusal. Formation of defects at the time of $t_{4}$ leads to reduction of resistance to refusal and at an invariance of regularity of aging - to definition of the predicted refusal time.

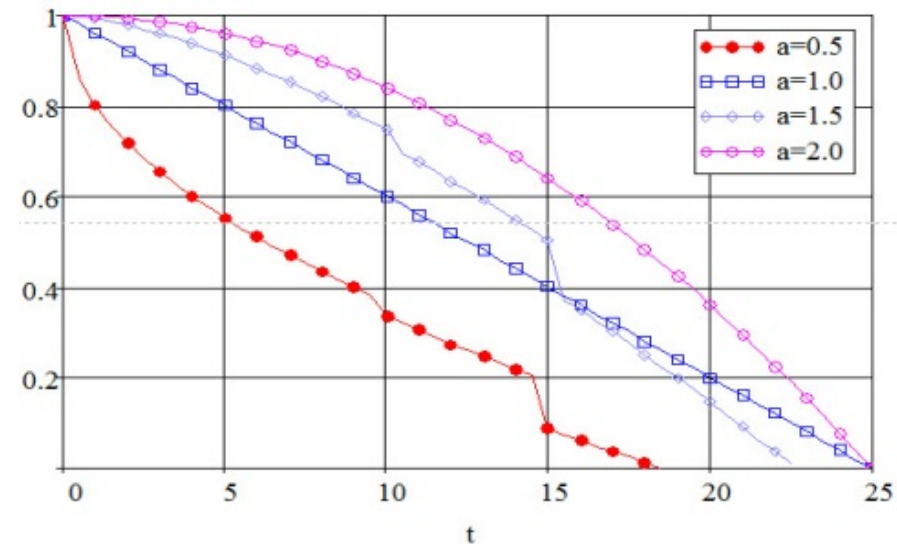

Figure 6 - Functions of resistance to refusal by formation of defects and their partial elimination.

For the definition of $t_{\text {otk }}$ and $t_{\text {ost }}$ requires knowledge of the $\Delta \Theta o t$ values which are function of the measured and rated values of diagnostic parameters. $\Delta \Theta o t$, indicator characterizing value of reduction of resistance to refusal is described in a look.

$$
\Delta \Theta o t=0.1 \cdot\left[X_{i} / X_{H}\right]^{m}
$$


here $X_{i}$ - value of the measured diagnostic parameter; $X_{H}$-rated value of diagnostic parameter; $\mathrm{m}$ - the indicator determined by a type of physical process in controlled object[6]. By the formation of several defects which values of diagnostic parameters are equal or exceed rated level, the indicator of i $\Delta \Theta o t$ is defined as the sum of indicators $\Delta \Theta_{o t i}$ of each defect:

$$
\Delta \Theta o t=\Delta \Theta_{o t 1}+\Delta \Theta_{o t 2}+\cdots+\Delta \Theta_{o t k}==\sum \Delta \Theta_{o t i}
$$

\section{Summary}

1. The considered mathematical model can be used as basic at calculation of thermal processes of the isolating materials in problems of nondestructive diagnostics of the main and distributive power stations in real time.

2. The mathematical model taking into account service conditions can be used in devices and systems of continuous diagnosing of power stations in thermal parameters.

\section{Acknowledgements}

This work was supported by Russia's Southern Federal University grant: "Theory and methods of energy-saving control for distributed generation, transportation and electricity consumption systems".

\section{References}

[1] Zalizny D. I. 2009. Mathematical modeling of thermal processes in power cables with plastic isolation. The bulletin of the Gomel state technical university of P. O. Suchoj. № 3.

[2] Poluyanovich N.K. \& M.Н. Дубяго. 2014. Study of characteristics of partial discharge for assessment of condition of electrical insulating materials of power supply system. 2013 International Conference on Renewable Energy and Environmental Technology (ICREET 2013) Applied Mechanics and Materials Vols.448-453 Trans Tech Publications, Switzerland: 2455-2460.

[3] Dubyago M.N., N.K. Poluyanovich. Study of characteristics of partial discharge for assessment of condition of electrical insulating materials of power supply system. Applied Mechanics and Materials. Trans Tech Publications, Switzerland Vols. 459.-2014. - p.70-75.

[4] Sitnikov V. F. \& Skopintsev V. A. 2007. Probabilistic and statistical approach to an assessment of resources of the electro network equipment in use//Electricity. № 11.

[5] Dubyago M.N. \& Poluyanovich N.K.2012 The Method of Nondestructive Testing and Prediction of Evolving Insulation Defect of Power Line Cable. INTERNATIONAL SAUM Conference on systems, Automatic Control and Measurements, Proceedings/ XI Trienial November 14-16: 418-422.

[6] Pshikhopov V. Kh. \& Medvedev M.Y. 2009. Estimation and control in complex dynamic systems. Moscow: Physical and Mathematical Literature: 295. 